\title{
Research of the Engineering Competence Framework: Analysis Based on the Engineering Education Accreditation Criteria of 15 Countries
}

\author{
Hongyu Lu ${ }^{a}$, Xiao Yu ${ }^{b}$, Xinmei Zhu ${ }^{c}$ \\ School of Economics \& Management, China Jiliang University, Hangzhou 310018, China. \\ aHongyu_L@163.com, bnellxx@163.com, ${ }^{\text {c5} 594762072 @ q q . c o m ~}$
}

\begin{abstract}
In the background of a knowledge economy and globalization, engineering talents, who are the carriers of engineering knowledge, have become a key factor determining the industrial level of all the countries in the world. To explore the competence demand of engineering talents under the trend of globalization and construct an engineering competence framework for cultivating international engineers, this study uses the engineering education accreditation criteria of 15 countries/regions as the research object. Text analysis is performed on the engineering competence requirements of engineering graduates. The key engineering competences are obtained after the samples are manually segmented, and the network of engineering and core engineering competences are constructed. This study explores the core components of engineering talents in the context of the Washington Accord as well as the interactive relationship between these components to provide a reference and quantitative analysis basis for talent training in engineering colleges and universities of China.
\end{abstract}

Keywords: Accreditation of engineering education, engineering competence, text analysis, competence framework, Washington Accord.

\section{Introduction}

Engineering education is responsible for the innovation and creation in a country, and plays a crucial role in China's higher education system. In the Undergraduate Specialty Catalogue of Higher Institutions [1], 169 majors, which account for one-third of the total number of majors in China, are set under the categories of engineering. The number of students pursuing engineering in China is three to five times higher than that in developed countries [2]. Therefore, it can be said that China is a well-deserved engineering education country.

However, China has yet to become a powerful country in engineering education. The goal of engineering education is to train qualified engineers. According to the Report on Quality of Engineering Education in China [3], the supply of engineering graduates cannot completely meet the demands of enterprises and industries. The employer's satisfaction score on the knowledge level, general competences, engineering competences, and comprehensive quality of engineering graduates was only 68.29 (out of 100). According to the World Competitiveness Report issued by the International Institute for Management Development [4], the number of qualified engineers in China's labor market is considerably lower than that in developed countries.

To solve the shortcomings of engineering education in China and promote industrial development, China established the "Excellence Program" in 2010 for promoting the reform of engineering personnel training and training world-class engineers. In 2015, the State Council officially issued the Made-in-China 2025 initiative, which emphasized five major projects and 10 high-tech fields, to achieve the goal of making China a manufacturing power. In 2017, the Ministry of Education successively developed the "Fudan Consensus" [5], "Tianda Action" [6], and "Beijing Guide" [7]and issued the Notice on the Development of Emerging Engineering Education Research and Practice [8]. The aforementioned strategies explore the engineering education system based on the Chinese model. The strategies indicate the urgent requirement for improving the quality of engineering talents and represent the ambition of building a strong country in engineering education.

A professional accreditation system is necessary for improving the quality of engineering education and building a powerful country in engineering education. The professional accreditation 
of engineering education is an output-centered educational orientation and student-centered educational concept [9]. Therefore, students' engineering competence is the core element of the professional accreditation criteria for engineering education. Moreover, to adapt to the rapid development in industrial technology, exploring the competence requirements of engineering talents with Chinese characteristics is essential in the new era. Engineering students must have engineering competence as per the Engineering Education Certification System of China [10]. However, the graduate competence requirement in the standard of China is the same as the engineering competence requirement in the Washington Accord, which does not completely conform to China's national conditions. The certification of education engineering in China began relatively late. Moreover, the education certification systems of some industrial powers in the world, such as the United States, Germany, and Japan, are excellent. By studying the advanced accreditation criteria of engineering education abroad, the international demand for the competences of engineering talents can be quickly and effectively determined. This information can play a guiding role in the construction of a competence framework more advanced than the international accreditation criteria for engineering talents.

\section{Literature Review}

In 2016, China became an official member of the Washington Accord, and the accreditation of engineering education once again became a field of considerable concern. Under the new technology development scenario, what type of demands does the industry have for the competence of engineering talents? Academic research has been conducted from different perspectives on engineering competence.

The engineering competency framework consists of a series of reference points that refer to specific learning outcomes and support the criteria system of engineering education accreditation [11]. At present, the most authoritative international engineering education accreditation criteria including ASIIN, EUR - ACE and ABET, if the competence requirements of these three engineering education criteria are integrated into the four-dimensional competence model defined by May and Terkowsky [12], we can find that the technical, professional engineering and methodological requirements are the most, and few requirements were related to the activity implementation competence. Therefore, engineering education should pay more attention to practice in the future development. The substantial equivalence between engineering education accreditation criteria is of great significance to the international circulation of engineering talents. Scholars Anwar and Richards [13] found that there is a clear correspondence between $\mathrm{ABET}$ and $\mathrm{EC}$ in the engineering competence requirements. Therefore, ABET can fully recognize projects approved by EC to reduce the workload.

In the research of Trevelyan [14], engineering competence is closely related to the life cycle of products, processes or systems. Meanwhile, the competence of engineering talents is closely related to cooperation and communication. Passow [15] defined the 16 general capabilities of the most important engineering practices, among which the most critical one is the competence of coordinating multiple competencies to accomplish a goal. Higher education plays a vital role in sustainable development. Fernandez et al. [16] built a model with five key competences: critical thinking, adapting to change, making decisions, problem solving, and multi-disciplinary teamwork. From the perspective of industrial demand, Xiao et al. [17] divided the engineering practice competence into engineering design competence, engineering application competence, engineering operation competence, engineering business competence and engineering communication competence. Irina [18] came up with the top five engineering competences: accurately set the work objectives, analyze, integrate and build system models.

The multi-angle research of the aforementioned scholars on engineering competence provides references and ideas to future generations for further exploration. However, the current research on engineering competences is based on qualitative discussion. This study conducted comprehensive research through text quantitative analysis on the competence requirements of engineering talents according to the engineering education accreditation criteria of major developed countries. 


\section{Method}

\subsection{Sample Selection.}

The sample objects are defined as the engineering education criteria established by the official signatories of the Washington Accord. All the criteria are established for undergraduate engineering professionals. The Washington Accord was initiated in 1989. The initiators and later-joining member states already had a mature competence framework for engineering education, which was based on their own national characteristics. Selecting the current engineering talent standard of these countries as the sample for analysis is feasible and scientific. In view of the short period of time for new signatories to conduct the certification of engineering education and the imperfect construction of the standard system of engineering talents, the signatories added after the China Association for Science and Technology are excluded. The samples are obtained from the documents published on the official website of the organization that joined the Washington Accord on behalf of their country. Fifteen valid documents are collected from organizations that made the relevant information public. The basic information of the samples is presented in Table 1.

Table 1. Basic information on research samples

\begin{tabular}{ccc}
\hline Name of the standard/certification file & Country/region & Association \\
\hline Washington Accord (IEA 2014) & Internationalism & IEA \\
CDIO Standard 2.1 (CDIO 2016) & Internationalism & CDIO \\
Criteria for Accrediting Engineering Programs (ABET 2018) & American & ABET \\
Accreditation of Higher Education Programs (EUCK 2014) & England & EUCK \\
EUR-ACE Framework Standards and Guidelines (NEAEE 2015) & Europe & NEAEE \\
A Guide to Outcomes-based Criteria (EC 2015) & Canada & EC \\
Competency Standard for Professional Engineer (EA 2017) & Australia & EA \\
Subject-specific Criteria (ASIIN 2011) & Germany & ASIIN \\
Regulations or the registered professional (EI 2015) & Ireland & EI \\
(JABEE 2015) & Japan & JABEE \\
2015) & Korea & ABEEK \\
Criteria for Accrediting Engineering Programs (KEC2015) (ABEEK & Russia & AEER \\
Professional Accreditation of Educational Programs in Engineering and & Technology (AEER 2014) & ECSA \\
Engmpetency Standard for Registration as a Professional Certificated & South Africa & \\
Engineer (ECSA 2017) & Hong Kong & HKIE \\
Professional Accreditation Handbook (HKIE 2013) & Chinese Taipei & IEET \\
\hline
\end{tabular}

\subsection{Text Preprocessing}

In text preprocessing, the engineering competence requirements are first selected from the 15 documents presented in Table 1. The engineering framework of countries and regions comprises two parts, namely the general scope of the competence described in phrases and the specific content of the competence described in long sentences, which are defined in this study as level-1 and level-2 competence, respectively. To facilitate quantitative text analysis and obtain specific engineering competence, the level-2 competence is manually divided into phrases, which are defined as the level3 competence. To ensure the objectivity of segmentation, specific rules are set as follows: (1) A level3 competence cannot occur more than once under the same level-2 competence. This rule is set because when a level- 2 competence has too much content, a level-3 competence may be repeatedly proposed. To ensure the rationality of the results, the repetition competence is only retained once. (2) The unity of synonyms. Different countries have different wording habits. Therefore, different words may be used to express the same or similar meaning. To enhance the reliability of the research, synonyms are expressed uniformly. (3) Elimination of unnecessary adjectives and adverbs. The 
constraint of adjectives and adverbs on words will lead to excessive dispersion of text analysis results. (4) Unity of dimensions. The description of competence in some samples is too specific and detailed to be compared with the description in other countries. Therefore, the expression of high-dimensional competence is reduced to the lowest dimension of the same type of competence. (5) Consistency of the expression. For example, "solution of problems" should be unified as "solve problems." (6) Unified spelling. The word "analyze" can be spelled as "analyse." Both words are unified as "analyze" in preprocessing. (7) Unity of singular and plural. (8) Unity of the part of speech. (9) Unified tense. Specific examples are presented in Table 2. A total of 990 level-3 competences were obtained after preprocessing.

Table 2. Example of level-3 competence

\begin{tabular}{ccc}
\hline $\begin{array}{c}\text { Level-1 } \\
\text { competence } \\
\text { (original) }\end{array}$ & Level-2 competence (original) & $\begin{array}{c}\text { Level-3 competence } \\
\text { (segmentation) }\end{array}$ \\
\hline Making & $\begin{array}{c}\text { Ability to gather and interpret relevant data and handle } \\
\text { complexity within their field of study, to inform judgements } \\
\text { that include reflection }\end{array}$ & $\begin{array}{c}\text { gather data } \\
\text { interpret data } \\
\text { handle complexity } \\
\text { awareness of societal } \\
\text { awareness of ethical } \\
\text { manage activities } \\
\text { manage projects } \\
\text { responsibility } \\
\text { make decisions }\end{array}$ \\
\hline
\end{tabular}

\subsection{The Word Cloud of Engineering Competence}

Word frequency analysis is conducted with the Word List function in AntConc, and 462 level-3 competences are identified. To present the analysis results succinctly, the level-3 competence frequency of AntConc is read in RStudio. The word cloud of engineering competence is drawn as illustrated in Fig. 1. In the word cloud, the frequency of engineering competence is represented by the word number. The most prominent engineering competences in Fig.1 are analyze, design, management, apply knowledge, and teamwork. "Analyze" includes the analysis of engineering systems, processes, activities, products, and problems. "Design" includes designing systems, components, processes, experiments, and solutions. "Management" includes system management, project management, quality management, risk management, and information management. "Apply knowledge" includes applied mathematics, science, engineering, information, and technology. "Teamwork" is the ability to function as a team member or leader in a multidisciplinary group. Although each country or region has different requirements on the details of engineering competence, the word cloud indicates that the international requirements on engineering competence have an obvious common trend. Therefore, the key engineering competences can be feasibly extracted from the engineering education accreditation criteria of many countries or regions.

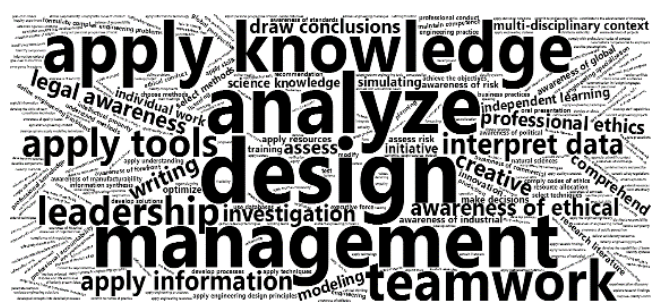

Fig. 1 Word cloud of engineering competence

\subsection{Acquisition and Reliability of the Key Engineering Competences}

The importance of an engineering competence is directly reflected by its frequency. In this study, the frequency of high and low word strings was divided by Zipf's Second Law to obtain the key engineering competences. In Zipf's Second Law, which is the distribution law of low-frequency 
words, a method is proposed to determine the demarcation point between high- and low-frequency words $[19,20]$. The demarcation point is obtained as follows:

$$
n=\frac{-1+\sqrt{1+8 I_{1}}}{2} \text {. }
$$

where $I_{1}$ indicates the number of words that appear once in the text. According to the AntConc analysis results, $I_{1}=362$ and $n=26.412$, which is rounded to 26 . Therefore, according to Zipf's second law, the top 26 most frequent engineering competences in this study are high-frequency competences, which are defined as the key engineering competences.

Table 3. Key engineering capacity table

\begin{tabular}{ccc}
\hline Frequency & Engineering competence & Category \\
\hline 28 & design & \\
25 & analyze & \\
24 & solve engineering problems & \\
21 & apply knowledge & \\
17 & apply methods & \\
12 & apply tools & \\
12 & mathematics knowledge & \\
11 & engineering knowledge & \\
9 & interpret data & \\
8 & apply information & \\
7 & conduct experiments & \\
24 & management & \\
21 & awareness of environmental & \\
20 & awareness of societal & \\
19 & communicate effectively & \\
18 & awareness of health & \\
17 & awareness of safety & \\
17 & teamwork & \\
13 & advance with the times & \\
13 & awareness of economic & \\
13 & life-long learning & \\
13 & responsibility & \\
12 & awareness of sustainability & \\
7 & leadership & \\
\hline
\end{tabular}

Among the key engineering competences presented in Table 3, "design" has the highest frequency (28 times) and is mentioned in the engineering education accreditation criteria of 15 countries/regions. It appears in the same criterion many times, which indicates its importance. The frequency of "ethical awareness" and "conduct experiments" is the lowest (7 times), nearly half of the engineering education accreditation criteria in the sample set include these two engineering competences. Thus, the setting of the 26 major engineering competences is reasonable. To facilitate subsequent analysis, the 26 major engineering competences are divided into two categories: professional knowledge and skill requirements, and comprehensive quality requirements. The design, analyze, solve engineering problems, apply knowledge, apply methods, apply tools, mathematics knowledge, engineering knowledge, interpret data, apply information, and conduct experiments competences belong to the professional knowledge and skill requirements category. The comprehensive quality requirements include 15 competences, such as management, environmental awareness, societal awareness, communicate effectively, awareness of health, awareness of safety, teamwork, advance with the times, economic awareness, life-long learning, and responsibility. 
Although the authors attempt to ensure objectivity in the process of artificial segmentation, there may exist some subjectivity. Therefore, to verify the accuracy of the frequency results of level-3 competences obtained with AntConc, the original text of level-2 competences without manual segmentation are imported into AntConc for text analysis. AntConc's default word segmentation method involves using spaces for word segmentation. Thus, the frequency obtained by this operation is only the frequency of words and not the frequency of phrases. In total, 3197 words and 828 types of words are obtained after importing the stop list and removing the words with no practical meaning, such as modal particles, adverbs, partial adjectives, prepositions, and connections. The top 26 words according to frequency are presented in Fig.2. This comparison indicates that words with level-2 and level-3 competence shave a consistent frequency distribution, which suggests that accurate and reliable results are obtained for the frequencies of the level-3 competences.

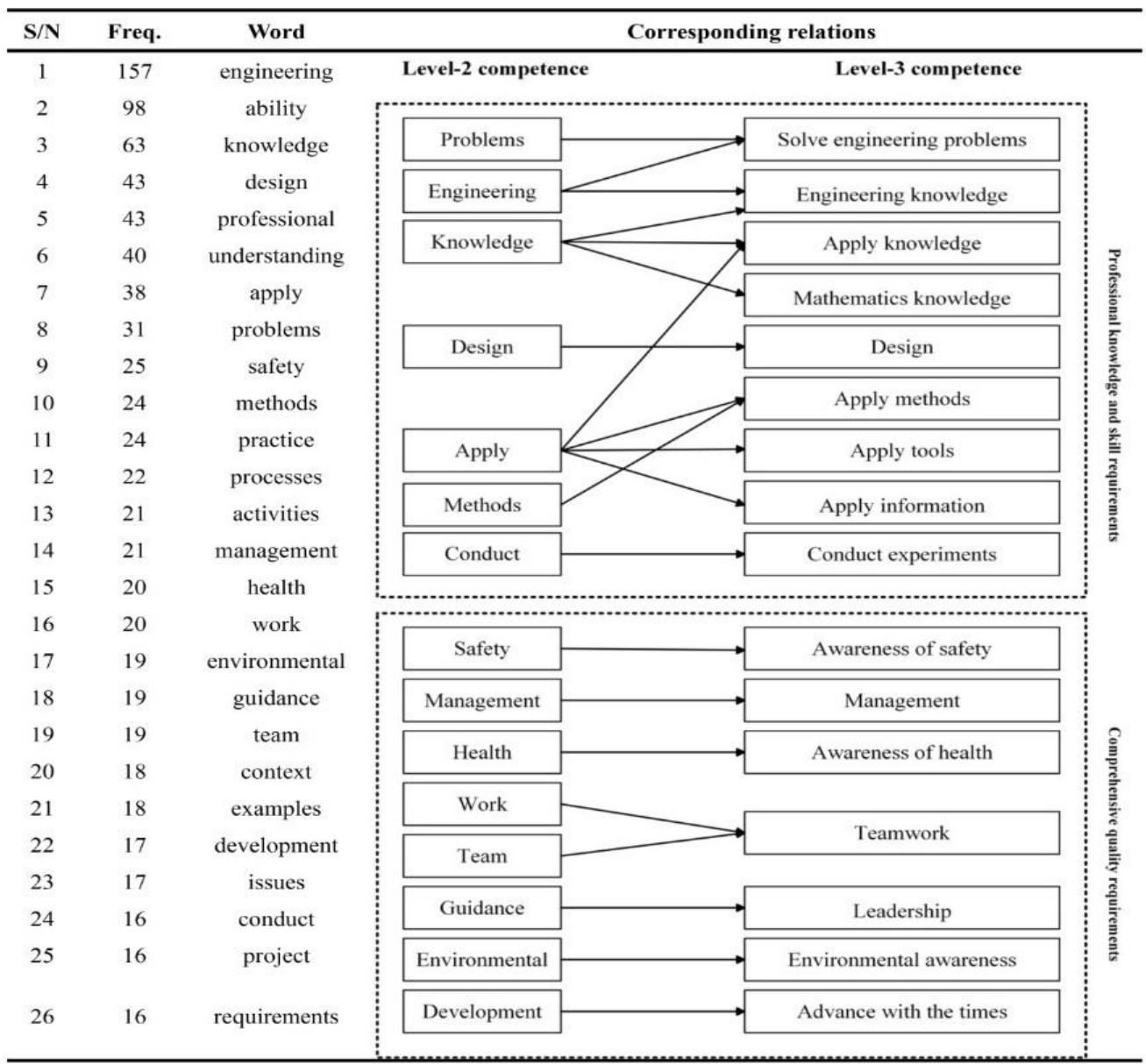

Fig. 2 High-frequency words of level-2 competences and their corresponding relations with level-3 competences

\section{Research on the Relationship between Engineering Competences}

\subsection{Construction of the Co-Occurrence Network of Engineering Competence}

To reduce interference and obtain an enhanced visualization effect, the engineering competences with frequencies higher than 1 are selected to construct the competence network. One node represents an engineering competence, the edge represents the interaction between two competences, and the edge weight represents the number of times that any two competences co-occur in the competence requirements text in 15 countries/regions [21]. A csv file containing the relations between the nodes and edges is imported into the Gephi software. After the software automatically sieves the edge with a weight of 0 , a competence network containing 100 nodes and 3082 undirected edges is obtained. The ForceAtlas 2 layout mode is selected, and a preview is obtained after layout optimization. 


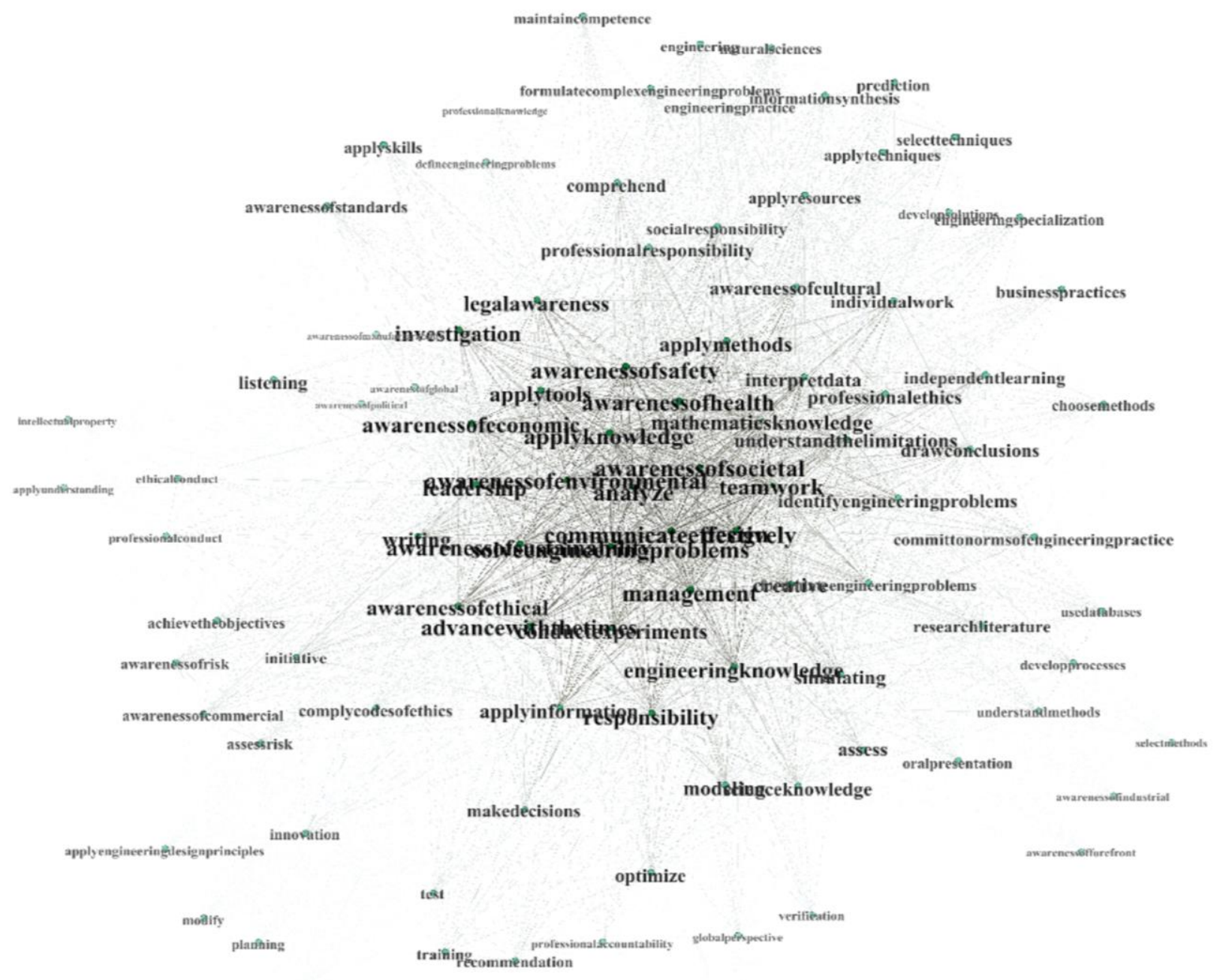

Fig. 3 Engineering competence network

The density of the engineering competence network is 0.623 , which indicates that 100 engineering competences have a relatively close relationship. For undirected weighted graphs, the average weighted degree is the best statistical parameter, followed by the average degree [22]. Therefore, only the average degree and average weighted degree of the network are statistically analyzed in this study. The equation for calculating the average degree (AD) of an undirected graph is given as follows:

$$
A D=2 \times \frac{e}{n} .
$$

where $e$ is the number of edges and $n$ is the number of nodes.

The equation for calculating the average weighted degree (WD) of an undirected graph is as follows:

$$
W D=\frac{\sum_{i}^{n} d}{n} .
$$

where $d$ is the degree and $n$ is the number of nodes.

The $\mathrm{AD}$ of the engineering competence network graph is 61.64. Thus, the average number of edges connected by each node in the network is 61.64 , which indicates that the engineering competence network has good overall connectivity. The average WD is 142.42 . Thus, the weight of the entire network edge is 142.42, which indicates that the co-occurrence frequency of engineering competences is relatively high.

\subsection{Construction of the Core Engineering Competence Framework}

The WD and AD of the engineering competence network obtained through preliminary optimization indicates that the network has a high degree of cohesion. Moreover, the relationship between the core competences cannot be observed through the network graph alone. According to 
the experiment, the best framework diagram is obtained when edges with weights of less than 13 are filtered (Fig.4). The framework diagram of core engineering competence is a three-dimensional competence framework with "communicate effectively" as the core. The four competences of communicate effectively, analyze, design, and solve engineering problems constitute a tetrahedron. The four competences interact, promote, and complement each other and are closely related with all the engineering competences. Moreover, "communicate effectively" is interrelated with the societal awareness, teamwork, and apply knowledge competences. The "communicate effectively" competence has a frequency of 19. It ranks eighth among the key engineering competences, but is at the center of the entire engineering competence network. From the perspective of frequency alone, "communicate effectively" is less important than the top seven competences. However, this competence is closely related to various other engineering competences and can be called the "transportation junction" of engineering competences. By contrast, although the frequencies of "management" and "environmental awareness" are high, they do not appear in the core of engineering competence network, which indicates that there exists no positive correlation between the importance and centrality of a type of engineering competency.

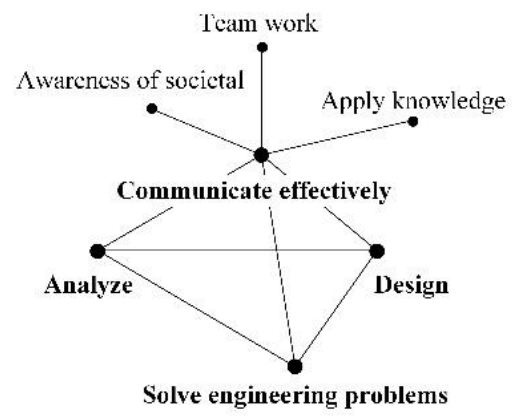

Fig. 4 Core engineering competence framework

\section{Conclusions and Recommendations}

The significance of this research is that the core engineering competence network is obtained through text analysis and social network analysis of the engineering competence requirements in mature engineering professional accreditation criteria. The core engineering competence network provides a comprehensive and objective reference for developing countries to formulate graduation requirements for engineering majors. It also provides a direction for colleges and universities to formulate training programs for engineering students.

The world demands a high comprehensive quality of engineering talents. The frequency distribution of the top 26 level-3 competences in the AntConc analysis results indicates that there exist only 11 competences related to professional knowledge and skill, which account for $421 \%$ of the total competences. Comprehensive quality requirements account for $581 \%$ of the total engineering competences. In the core engineering competence network, there exist three professional knowledge and skill requirements and four comprehensive quality requirements. The training direction of higher engineering talents has developed from the initial "professional engineer" and "knowledge engineer" to the "comprehensive engineer" under an interdisciplinary background, which is caused by the interdisciplinary infiltration resulting from social progress and technological development. The ideas of multi-disciplinary and hyper-disciplinary training are increasing in popularity, and this demand trend will guide the development direction of Chinese engineering education.

In the training of engineering talents, the management should grasp the main engineering competences of engineering talents and pay attention to the relationship between engineering competences. Engineering competence is a student-centered output orientation index. Its framework is the foundation of the entire engineering education accreditation criteria system, which plays a guiding role in engineering talent training. The top 26 engineering competences with the highest frequency among the level-3 competences are the foundation and mainstream requirements for cultivating the world's engineering talent. These competences are frequently listed in the engineering 
education accreditation criteria documents of various countries/regions, which indicate their importance. To ensure the smooth international circulation of Chinese engineering talents and to eliminate professional barriers, considerable attention should be paid to these major engineering competences.

The quality assurance system of engineering talent cultivation should be built around the correlation among the seven engineering competences in the core engineering competence framework to ensure the realization of core competence. Frame-based collaborative cultivation of engineering competence can enhance the interaction among various competences and cause the overall competence of engineering talents to develop in a positive direction.

The characteristics of the engineering talent training system must be enhanced. In the word frequency analysis results of level-3 competence, there exist 362 level-3 engineering competences with a frequency of 1 . These competences account for more than $78.31 \%$ of the total number of engineering competences (462). This information indicates that the 15 countries/regions in the sample have considerable differences in the requirements for the competences of engineering talents. This study presents 26 key competences for the undergraduate training of engineering students. However, in different countries or regions, the competence requirements for engineering talent may have various local features. In countries/regions that are formal members of the Washington Accord, the requirements for engineering professionals are often higher than those in the Washington Accord. For the cultivation and construction of China's engineering talent, lessons can be drawn from foreign advanced engineering personnel certification standards. However, these standards cannot be completely copied. The Washington Accord should be regarded as the threshold for international engineering education accreditation. China's engineering personnel certification standard should be rooted in national conditions, respond to the needs of the domestic market, and build an engineering talent competence framework with Chinese characteristics. The developed framework should have higher requirements than the international standard.

\section{Acknowledgments}

This work was supported by the Special Task Project for Humanities and Social Sciences Research of the Ministry of Education of China (Program NO.18JDGC035), and Science and Technology Innovation and Projects for College Students in Zhejiang Province (No. 2019R409045). The authors thank all the scholars working in the field of engineering competence. Their research provided the theoretical foundation and ideas for the completion of this article. The authors also thank Xu Qunsong for his help in data processing.

\section{References}

[1]. Information on: http://www.moe.gov.cn.

[2]. Higher Education Teaching Evaluation Center of the Ministry of Education. Quality Report of China Engineering Education. Educational Science Pub, 2016.

[3]. Information on: http://edu.people.com.cn.

[4]. Information on: https://www.imd.org.

[5]. Bureau of Higher Education. Fudan Consensus on emerging engineering education construction. $2017 \mathrm{a}$.

[6]. Bureau of Higher Education. Emerging engineering education construction action Route (Tianda Action). 2017b.

[7]. Information on: http://www.moe.gov.cn/.

[8]. Bureau of Higher Education. Notice of the Bureau of Higher Education of the Ministry of Education on the research and practice of Emerging Engineering Education. 2017c. 
[9]. Leshner, A. I., Student-centered, modernized graduate STEM education. Science. Vol.360 (2018) No.6392, p 969-970.

[10]. Information on: http://www.ceeaa.org.cn/.

[11]. Yangqiong, Q: Study on the qualification framework based on body of knowledge: taking engineering as an example ( $\mathrm{Ph}$. D, Zhejiang University, China, 2012).

[12]. May, D., Terkowsky, C. What should they learn? A short comparison between different areas of competence and accreditation boards criteria for engineering education. Engineering Education 4.0. Springer International Publishing, 2016.

[13]. Anwar, A. A., Richards, D. J., Comparison of EC and ABET accreditation criteria. Prof. Issues Eng. Educ. Pract. Vol.144(2018) No. 3.

[14]. Trevelyan, J., Reconstructing engineering from practice. Engineering Studies. Vol.2(2010) No.3, p. 175-195.

[15]. Passow, H. J., Passow, C. H. What competencies should undergraduate engineering programs emphasize? a systematic review. J. Eng. Educ. Vol.106(2017) No.3, p. 475-526.

[16]. Fernandez-Sanchez, G., Bernaldo, M. O., Castillejo, A., et al. Proposal of a theoretical competence-based model in a civil engineering degree. J. Prof. Issues Eng. Educ. Pract. Vol. 141(2015) No. 2.

[17]. Xiao, Y., Mingshun, S., Yueyi, Z. Research on the practical competence framework of engineering talents from the perspective of industry and its industry-university fit. Research in Higher Education of Engineering. Vol.16 (2014) No.2, p. 85-88.

[18]. Irina, G. S. Professional competences necessary for the bachelor-degree-holding engineer specialising in engineering industries. Pacific Science Review. Vol.16 (2014) No.2, p. 85-88.

[19]. Andrew, D. B. A law of occurrences for words of low frequency. Inform. Control. Vol.10 (1967) No.4, p. 386-393.

[20]. Qinglan, S., Shaw, D., Davis, C. H. A model for estimating the occurrence of samefrequency words and the boundary between high- and low-frequency words in texts. J. Am. Society for Information Science. Vol.50 (1999) No.3, p. 280-286.

[21]. Akhtar, N., Social network analysis tools. 2014 Fourth International Conference on Communication Systems and Network Technologies. 2014.

[22]. Yong, L., Network data visualization and analysis of the Chinese tutorial on Gephi. Electronics Industry Pub., 2017. 